\title{
超微粒子超硬合金の曲げ疲労特性
}

\author{
阪上楠彦, 河野 信一, 山本勉 \\ ダイジェットエ業(侏)，テ 547-0002 大阪市平野区加美東 2-1-18.
}

\section{Bending Fatigue Characteristics of Micrograin Carbide Alloys}

\author{
Kusuhiko Sakagami, Shinichi Kouno and Tsutomu Yamamoto \\ Dijet Industrial Co., Ltd., 2-1-18 Kamihigashi Hirano-ku, Osaka 547-0002.
}

Received January 16, 2003

\begin{abstract}
SYNOPSIS
As micrograin carbide alloys with average WC grain size below $1 \mu \mathrm{m}$ have been widely used for cutting tools and wear resistant tools, it is very important to acquire knowledge on bending fatigue characteristics of the alloys in order to estimate and improve a tool life. Therefore, in this study, the characteristics of three points bending fatigue in micrograin $\mathrm{WC}-6 \sim 15$ mass $\% \mathrm{Co}-0.4 \sim 1.2 \mathrm{mass} \% \mathrm{Cr}_{3} \mathrm{C}_{2}$ alloys with grain size of $0.8 \mu \mathrm{m}$ which were treated by HIP or Sinter-HIP process was mainly investigated in relation to a fracture origin.

The results obtained were as follows: (1) As regarding the effects of Co content on bending fatigue of the HIPtreated alloys, the fatigue life was almost same in $6 \sim 12$ mass $\%$ Co alloys, but it decreased in 15 mass $\%$ Co alloy. (2) The fracture origin observed on the fractured surface after bending fatigue test in the HIP-treated alloys was Co pool with the step-shaped form in all cases. (3) There was some correlation between the size of Co pool origin and the fatigue life under same applied stress. In the Sinter-HIP treated alloys, the fatigue life was considerably improved due to the decrease of the size of Co pool defect in the microstructure.
\end{abstract}

KEY WORDS

micrograin carbide alloys, bending fatigue, Sinter-HIP, fracture origin, Co pool defect

\section{1 緒 言}

WCの平均粒径が $1.0 \mu \mathrm{m}$ 以下の超微粒子超硬合金は,ソリッ ドエンドミルやドリル等の切削工具や電子部品加工用工具等 に広く利用されており，本系合金の工具寿命を予測するには その疲労特性を知ることが重要と考えられる。これまでに著 者らは，主に中粒 (約 $1.6 \mu \mathrm{m}$ ) のWC-12mass\%Co 超硬合金に ついて3点曲げ疲労試験を行い, HIP処理や表面研削状態およ びコーティング処理の影響等について報告1を行ってきたが， 本報では粒成長抑制剂として $\mathrm{Cr}_{3} \mathrm{C}_{2}$ を添加した超微粒子超硬合 金を用いてその 3 点曲げ疲労特性を調べ，工具寿命の向上に 役立てることを目的とした。

\section{2 試料及び実験方法}

疲労試験に用いた材料は,WC-6 15 mass\%Co-0.4 1.2mass\% $\mathrm{Cr}_{3} \mathrm{C}_{2}$ 組成の平均WC粒径 $0.8 \mu \mathrm{m}$ の中炭素超微粒子合金で，通 常焼結 (1603 $1673 \mathrm{~K} \times 1.8 \sim 3.6 \mathrm{ks}$; 高 Co 合金任ど低温短時
間焼結 $)$ 後に HIP 処理 $(1573 \mathrm{~K} \times 3.6 \mathrm{ks}, 100 \mathrm{MPa}$ の $\mathrm{Ar}$ 中) を施 し作製した.また,WC-12mass\%Co-1.0mass\% $\mathrm{Cr}_{3} \mathrm{C}_{2}$ 組成では， Sinter-HIP 処理 $(1623 \mathrm{~K} \times 1.8 \mathrm{ks}+3.6 \mathrm{ks}, 5 \mathrm{MPa} の \mathrm{Ar}$ 中 $)$ 合金も 作製した.

3 点曲げ疲労試験には島津製作所製サーポパルサーEHFEA20型を用い，試験片形状は $6 \times 12 \times 33 \mathrm{~mm}$ とし，\#200のダイ ヤモンドホイールで研削加工をした.3点曲げ疲労試験には支 点間距離 $28 \mathrm{~mm}$ の治具を用い，疲労条件を SIN 波形の振動数 $5 \mathrm{~Hz}$ とし, 0〜設定最大応力の範囲で繰り返し負荷を与え, 破 壊するまでの絽り返し数を求めて S-N 曲線を作成した. 3 点 曲げ疲労寿命の評価はS-N曲線の相対的な位置関係から優劣 を判定した.

また, 抗折力 $(\mathrm{n}=5)$, 硬さ測定およびX線回折法による $2 \theta$ $\sin ^{2} \psi$ 法を用いて試験片加工面のWC相(11・1) 面の残留応力測 定を行うと共に, 破壞試駼片についてはSEMによる破壊起点 の観察を行った。なお, 上記の疲労試験に供した試験片の特 
Table 1 Some properties of micrograin WC-6 15 mass $\%$ Co-0.4 1.2 mass $\%-\mathrm{Cr}_{3} \mathrm{C}_{2}$ alloys made by Normal Sintering (NS) plus Hot Isostatic Pressing (HIP) and Sinter-HIP processes.

\begin{tabular}{|c|c|c|c|c|c|}
\hline $\mathrm{Co} / \mathrm{Cr}_{3} \mathrm{C}_{2}$ (mass\%) & $6.0 / 0.4$ & $10.0 / 0.8$ & \multicolumn{2}{|c|}{$12.0 / 1.0$} & $15.0 / 1.2$ \\
\hline Methods of sintering & NS + HIP & NS + HIP & NS + HIP & Sinter-HIP & NS + HIP \\
\hline T.R.S. (GPa) & 3.6 & 3.9 & 4.0 & 4.1 & 3.6 \\
\hline Hardness ( $\left.\mathrm{H}_{\mathrm{R}} \mathrm{A}\right)$ & 93.0 & 91.8 & 91.2 & 91.2 & 90.4 \\
\hline $\begin{array}{c}\text { Surface residual stress of } \\
\text { WC (11.1) (GPa) }\end{array}$ & -2.8 & -2.6 & -2.5 & -2.5 & -2.3 \\
\hline
\end{tabular}

性值はTable 1に示す通りであって,抗折力は10および12mass\% Co 合金で 6 および 15 mass\% Co 合金よりも高い値を示したの に対し，硬さと圧縮残留応力は高Co合金ほど低下した。

\section{3 実験結果と考察}

Fig.1に Co 量を 6〜 15 mass\%の間で変化させ, HIP 処理を 行った超微粒子合金の 3 点曲げ疲労試験における $\mathrm{S}-\mathrm{N}$ 曲線を 示した.これより，Co量が6〜12 mass\%の間では疲労寿命に 大きな差は生じなかったが, Co量が 15 mass\%の場合に疲労寿 命の低下が見られた．超硬合金の 3 点曲げ疲労寿命は，その 抗折力の強度順位に従う場合が経験的に見られた ${ }^{2}$ が, 本系 合金の場合抗折力がやや低い 6 mass\%Co合金において疲労寿 命の低下は見られなかった.これは，すでに報告している曲 げ疲労寿命と残留応力の関係 ${ }^{1}$ から, 6 mass\% Co 合金が比較的 低Co量の合金であるため試験片表面の圧縮残留応力が同じ抗 折力の 15 mass\% Co 合金に比べて高かったこと(Table 1 参照) か，主原因と考えられた。

Fig.1において破壊した試験片の疲労破壊起点をすべて観察 した結果, Co 量に係わらず全ての試験片で Fig.2に示された 疲労破壞特有の階段状破面を呈する $\left.\mathrm{Co} \mathrm{pool}^{2}\right)^{2}$ が起点となって

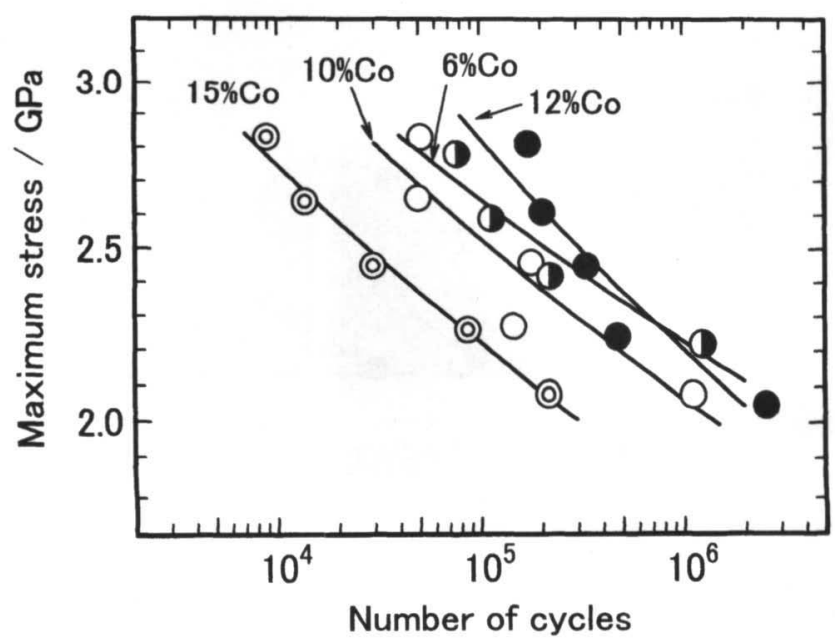

Fig.1 S-N curves on bending fatigue of micrograin WC- $6 \sim 15$ mass $\% \mathrm{Co}-0.4 \sim 1.2$ mass $\% \mathrm{Cr}_{3} \mathrm{C}_{2}$ alloys treated by HIP.
いた. Table 2には以前の結果 $\left.{ }^{1,2}\right)$ に基づいて調べたWC粒度と 疲労破壊起点の種類およびCo pool起点で破壊する割合を示し ており, 平均WC粒径が小さくなるほど, Co poolが破壊起点 になりやすい傾向が見られた.このように破壞起点がCo pool 部のみとなることは, HIP 処理を施した本系合金の曲げ疲労 における特徵と言うことができる.

この曲げ疲労時のCo pool起点に関してはすでに報告)して いる通り, HIP処理前のPoreから発生したものであるので, 通 常焼結においてはWC 粒径が小さいほど Pore が発生しやす かっだ こと, および $\mathrm{Cr}_{3} \mathrm{C}_{2}$ 添加の超微粒子合金では粗粒 WC がほとんど発生していなかったことから, Co pool部のみで疲 労き裂( が生じて破壊起点となったものと考えられる.

なお, Fig.3には比較のために本試験に用いた超微粒子合金 の抗折破面における代表的な破壊起点を示したが, この場合 は疲労試験で生じたCo poolが起点となる場合はなく, 写真の ような WC 粒の凝集部と思われる所が起点となる場合が大半 であった．このように HIP 処理を施した超微粒子合金におい ては, 抗折試験と曲げ疲労試験での破壊起点の種類は全く異 なっていた.

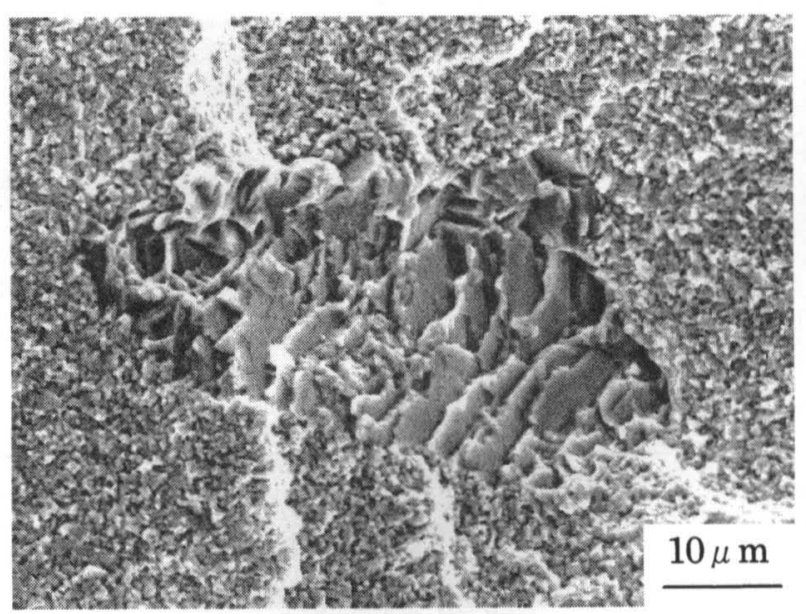

Fig.2 An example of SEM image of fracture origin observed in bending fatigue-fractured test piece of micrograin WC-12 mass $\% \mathrm{Co}-1.0$ mass $\% \mathrm{Cr}_{3} \mathrm{C}_{2}$ alloy treated by $\mathrm{HIP}$. 
Table 2 Kinds of fracture origin and proportion of Co pool origin observed in bending fatigue-fractured test piece of HIP treated WC-12 mass $\% \mathrm{Co}-1.0$ mass $\% \mathrm{Cr}_{3} \mathrm{C}_{2}$ alloy with different $\mathrm{WC}$ grain size.

\begin{tabular}{|c|c|c|c|}
\hline & $\begin{array}{c}\text { Coarse-grain } \\
\text { alloy }\end{array}$ & $\begin{array}{c}\text { Medium-grain } \\
\text { alloy }\end{array}$ & $\begin{array}{c}\text { Micrograin } \\
\text { alloy }\end{array}$ \\
\hline $\begin{array}{c}\text { Average WC grain size } \\
(\mu \mathrm{m})\end{array}$ & 3.0 & 1.6 & 0.8 \\
\hline Kinds of fracture origin & WC & WC / Co pool & Co pool \\
\hline $\begin{array}{c}\text { Proportion of Co pool } \\
\text { origin (\%) }\end{array}$ & 0 & 34 & 100 \\
\hline
\end{tabular}

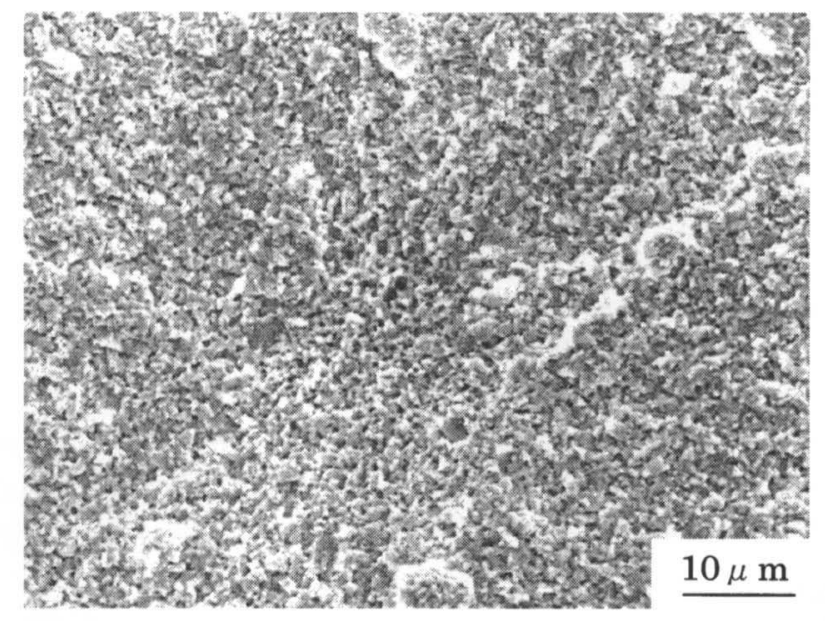

Fig.3 An example of SEM image of fracture origin observed in transverse rupture- fractured test piece of micrograin WC12 mass $\%$ Co- 1.0 mass $\% \mathrm{Cr}_{3} \mathrm{C}_{2}$ alloy treated by HIP.

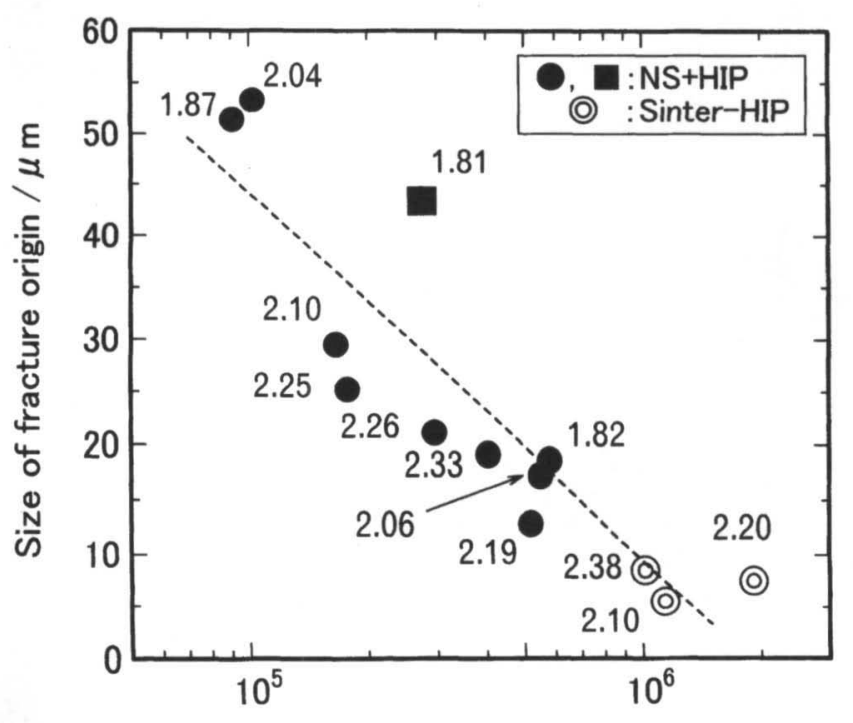

Number of cycles

Fig.4 Relation between size of fracture origin and number of cycles up to bending fatigue fracture at maximum stress of $2.45 \mathrm{GPa}$ in micrograin WC- 12 mass $\% \mathrm{Co}-1.0$ mass $\% \mathrm{Cr}_{3} \mathrm{C}_{2}$ alloy made by NS + HIP and Sinter-HIP processes. Number in the figure indicates bending stress $(\mathrm{GPa})$ acted on fracture origin.
ここで, WC-12mass\%Co-1.0mass\% $\mathrm{Cr}_{3} \mathrm{C}_{2}$ 組成の超微粒子合 金における Co pool の起点寸法と疲労寿命の関係を, $2.45 \mathrm{GPa}$ の最大曲げ応力で疲労破壊させた10個の試験片について調べ た. その結果を Fig.4に示す. なお, 図中の数字は起点に作用 した応力値 ${ }^{5}$ を表している.これより, Co poolの起点寸法と 疲労寿命の間にはある程度の相関性をもつことが分かり, 繰 り返し負荷の過程で生じる疲労き裂(4)長さがCo pool起点の寸 法と比例するものと推察される.さらに, 口印の試料のよう にCo pool起点寸法が大きいにも係わらず疲労寿命の長い場合 も見られたが,これは起点に作用した応力が比較的小さい, 換言すればFig.5に示すように破壊起点の位置が試験片の張力 面およびスパン中央部から離れた位置にあるために, この様 な結果になったものと考えられた. 従って, すでに報告され ている抗折強度の場合5) と同様に破壊起点位置も同時に疲労 強度に影響するものと思われる。

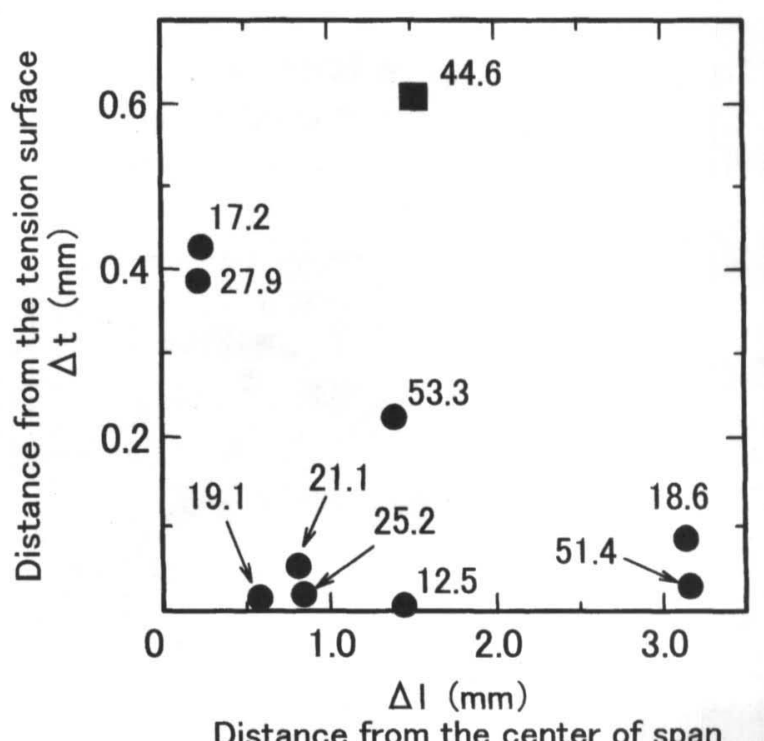

Fig.5 Location distribution of Co pool origin fractured by bending fatigue at maximum stress of $2.45 \mathrm{GPa}$ in micrograin WC12 mass $\%$ Co- 1.0 mass $\% \mathrm{Cr}_{3} \mathrm{C}_{2}$ alloy made by NS + HIP Number in the figure indicates the size $(\mu \mathrm{m})$ of Co pool origin. 


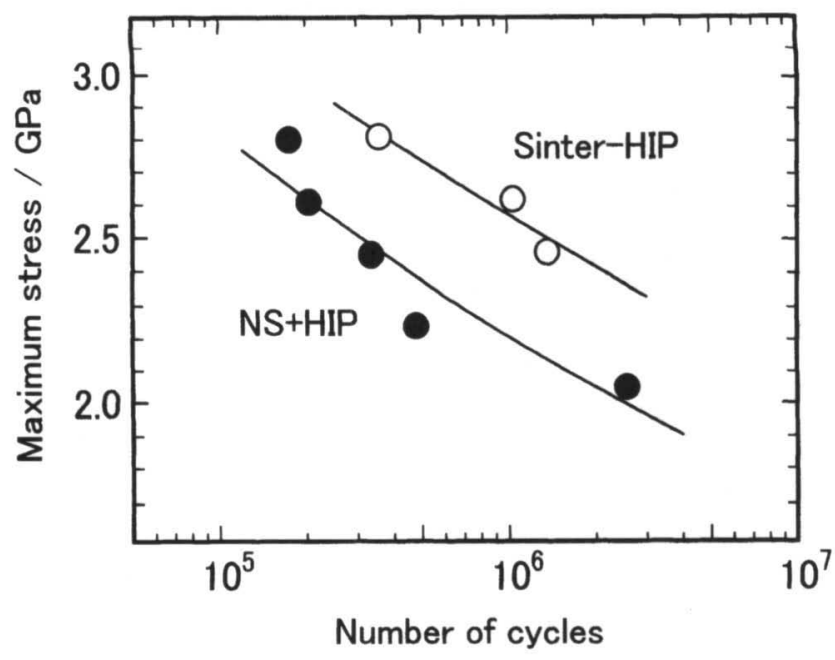

Fig.6 S-N curves on bending fatigue of micrograin WC-12mass \% Co-1.0 mass $\% \mathrm{Cr}_{3} \mathrm{C}_{2}$ alloy made by NS $+\mathrm{HIP}$ and SinterHIP processes.

以上のようなFig.4の関係から, 超微粒子合金の曲げ疲労破 壊起点となるCoの欠陥寸法を出来る限り小さくすることが曲げ 疲労寿命の改善につながると予測できるので,その一方法として 考えられるSinter-HIP処理を用いた場合について検証を行った.

Fig.6は通常焼結後 HIP 処理を施した場合と Sinter-HIP 品の S-N曲線である.これより, Sinter-HIP処理品は通常烤結後HIP 処理を施した場合よりも，抗折力では僅かな増加であったが (Table 1参照), 疲労寿命は全体的に大きく改善されているこ とが分かった.この Sinter-HIP品における, $2.45 \mathrm{GPa}$ の最大曲 げ応力で疲労破壊させた 3 個の試験片についてCo起点寸法を 調べて Fig.4の関係図の中に@印で示した.これより, SinterHIP 品ではCo起点寸法が $10 \mu \mathrm{m}$ 以下に減少した結果, 曲げ疲 労寿命が改善されたことが確認できた.

Fig.7 は Sinter-HIP 品の疲労破壊起点の SEM およびCOMPO (組成) 像である. SEM 像より, Sinter-HIP 品では前述の HIP 品の場合に見られたCo poolの階段状の形態が明瞭でなくなつ ていた.更にCOMPO像からはこれまでの場合とは異なり,Co pool 内 (灰色部)にWC粒 (白色部) を多数取り込んだ形で形 成された, 微小な Co rich 部となっていることが観察された. このように Sinter-HIP品ではCo起点の寸法が減少しただけで なくその破面形態にも変化が生じていた.

\section{4 結 論}

HIP および Sinter-HIPにより作製した平均粒径 $0.8 \mu \mathrm{m}$ の WC$6 \sim 15$ mass $\%$ Co- $0.4 \sim 1.2$ mass $\% \mathrm{Cr}_{3} \mathrm{C}_{2}$ 超微粒子合金の 3 点曲げ 疲労特性を調べ, 下記の結果が得られた.

(1) HIP品における疲労寿命に及ぼすCo量の影響については, 疲労寿命は 6〜 12mass\%Co 合金では大差なかったが, 15 mass\%Co 合金において低下した.

(2) HIP品では, 曲げ疲労試験後の破面にみられる破壊の起点 はすべて階段状の破面形態を呈するCo pool であった.

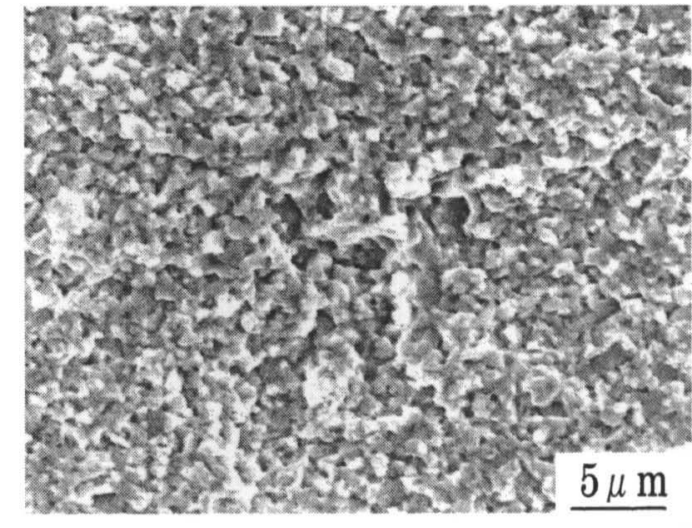

SEM-image

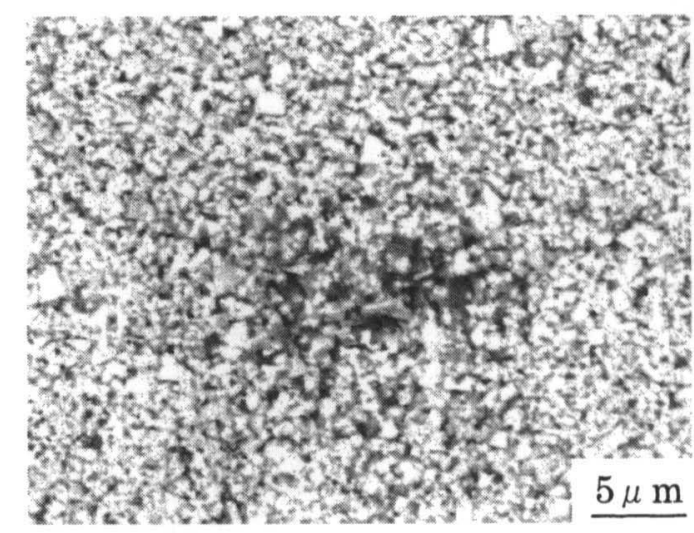

COMPO-image

Fig.7 SEM and COMPO images of fracture origin observed in bending fatigue fractured test piece of micrograin WC-12 mass $\% \mathrm{Co}-1.0$ mass $\% \mathrm{Cr}_{3} \mathrm{C}_{2}$ alloy made by Sinter-HIP process.

(3) 同一応力下での破面上のCo pool起点寸法と疲労寿命との 間には,ある程度の相関性があることが分かり, Sinter-HIP 処理品では組織中のCo pool欠陥寸法が減少することによ り, 曲げ疲労寿命が向上した。

\section{文献}

1) 阪上楠彦, 河野信一, 山本勉: "WC-12 mass\% Co 超硬合金 の曲げ疲労特性に及ぼすHIP処理および表面性状の影響", 粉体および粉末治金, 49(2002)306-311.

2) 阪上楠彦, 河野信一, 山本勉: "WC- 12 mass\% Co 超硬合金 の曲げ疲労特性", 粉体粉末冶金協会平成 13 年度春季大会 講演概要集, (2001)177.

3) 鈴木寿, 棚瀬照義: "WC-Co超硬合金の抗折力に及ぼす炭化 物粒度, 結合相量の影響", 日本金属学会誌, 40(1976)726-732.

4) 富士原由雄, 植田文洋, 正富宏明, 鈴木寿: " 熱間静水圧娔 結した WC-12\%Co 合金の疲労 ", 粉体および粉末冶金, 27 (1980)181-184.

5) 鉿木寿, 林宏爾 : "WC-10\%Co 超硬合金の抗折強度と破壊 の起源との関係", 日本金属学会誌, 38(1974)1013-1018. 